\title{
Pharmacological Therapies of Obesity: A Review of Current Treatment Options
}

\author{
H. Peter BACHeR ${ }^{1, *}$, Gillian M. ShePherd ${ }^{1}$, and Udo F. Legler ${ }^{2}$ \\ ${ }^{1}$ Abbott Laboratories, Department of Global Research and Development, AP-30-3, 200 Abbott Park Road, Abbott Park, IL 60064-6145, USA, \\ ${ }^{2}$ Abbott GmbH \& Co. KG, Department of Global Research and Development, Postfach 2108 05, 67008 Ludwigshafen, Germany
}

(Received October 20, 2009; Accepted October 21, 2009)

\begin{abstract}
Over the last decade, the incidence of overweight and obesity has nearly doubled in many countries and is considered a pandemic. Obesity was identified as a major risk factor for cardiovascular disease as the same level as smoking and diabetes. Visceral fat is considered one of the key contributors to outcome and certain ethnic groups such as Asians seem to be more affected than others. Weight reduction through lifestyle changes was found to be impactful to improve overall health, but weight loss and maintenance thereof is limited and difficult to sustain. Surgical intervention demonstrated a greater weight loss in the severely obese and was associated with improved all-cause mortality. Despite numerous pharmacological targets and a high medical need, only few drugs have been successfully developed. Earlier studies with amphetamine-derived compounds showed significant weight loss but their critical safety profiles led to market withdrawals and disappointment. More recent compounds; orlistat - a lipase inhibitor, rimonabant - a cannaboid-1-receptor antagonist, and sibutramine - a combined serotonin/norepinephrine re-uptake inhibitor, all demonstrated similar significant efficacy; however, they carry specific safety profiles making them unsuitable for every patient. The main limitation of pharmacotherapy is the absence of clear benefit-risk assessments through outcome studies. Such a study - the SCOUT trial - was designed to compare sibutramine versus placebo and the effect on morbidity and mortality in nearly 10,000 obese patients with additional risk factors. Such studies could provide new scientific evidence for obesity treatment and may support future pharmacological approaches.
\end{abstract}

Keywords: Obesity, Pharmacotherapy, Weight management, Orlistat, Rimonabant, Sibutramine

\section{OBESITY, A WORLDWIDE RISK FOR CARDIOVASCULAR OUTCOME}

Globally, the leading causes of mortality are dominated by ischemic heart and cerebrovascular diseases. Over 12.4 million patients (23.2\%) die annually from conditions which are contributed to arteriosclerosis (Neal et al., 2002). In comparison, the HIVIAIDS death incidence is approximately 2.3 million per year $(4.2 \%)$. Current data indicate that in more affluent countries excess weight has become the third leading contributor to premature death and disease, after smoking and blood pressure (Lopez et

${ }^{*}$ Corresponding author

Tel: +1-847-936-3098 Fax: +1-847-935-3103

E-mail: peter.bacher@abbott.com al., 2006). Prospective data have shown that obesity is causally linked to major problems of premature death and cardiovascular disease, with an impact that is equivalent to that of heavy smoking (Prospective Studies Collaboration, 2009). Visceral obesity has also been identified as a stand-alone risk factor for myocardial infarction and had a similar increased risk of an approximately 3 times - similar to smoking and hypertension (Yusuf et al., 2004). Abdominal fat accumulation independently increases cardiovascular risk, so in middle-aged individuals, waist circumference, a surrogate marker for abdominal fat, may predict the development of stroke, myocardial infarction and cardiovascular mortality as well as diabetes in non-diabetic patients (Yusuf et al., 2005).

Overweight and obesity has a major impact on global health, for example, its prevalence has already reached 
over $50 \%$ in the USA and is significantly increasing in countries with Western life style. Diabetes and hypertension are consequences of obesity and are directly linked to increased Body Mass Index (BMI). Recent studies revealed that the correlations are different among races. Orientals are much more prone to develop obesity-related diseases than Caucasians (Huxley et al., 2008) confirming earlier reports that Asians (including Indians) have a significantly higher concentration of visceral fat, whereas, subcutaneous fat tissue did not reach a statistical difference versus Caucasians. Since it was also proven that visceral fat is the main contributor to outcome, specific therapies become crucial to target this condition. As a consequence, national guidelines in some Asian countries set the target for treatment lower than in the Western hemisphere (W.H.O. Expert Consultation, 2004).

\section{OBESITY - DOES INTERVENTION HELP?}

Already a decade ago, studies of weight loss achieved through lifestyle changes such as caloric restriction and increased exercise in men with impaired glucose tolerance improved all-cause mortality by more than $50 \%$ over a 12-year follow-up. The study showed similar reductions for cardiovascular death, but the data did not reach statistical significance. It is important to realize that weight loss achieved by the lifestyle intervention group could be considered as only moderate with a percentage weight change of -2.3 to $-3.7 \%$ over the control group $(-0.5$ to $-1.7 \%)$ (Eriksson and Lindgärde, 1998).

Management of obesity and its related conditions poses a major clinical challenge. For most people, particularly those at high cardiovascular risk, treatment by means of such lifestyle measures alone is inadequate and it is possible to postulate that the addition of specific pharmacotherapy or bariatric surgery could provide a greater effect size.
The Scandinavian Obesity Study (SOS) addressed the surgical aspect. Patients with morbid obesity indicative for surgical intervention were compared to a non-surgical control group. In the surgical group as might be expected, there was a significantly greater drop in body weight of up to $-30 \%$ which resulted in a significant reduction of mortality over the 14-year follow-up period. An additional important finding was the difference in mortality versus the control group which only became apparent approximately 5 years after surgery (Sjöström et al., 2007). This supports the hypothesis that obesity treatment strategies should be of long-term nature.

The open question remains: What results could be achieved through pharmacological intervention?

\section{OVERVIEW OF DRUG THERAPIES}

Drug treatment for obesity has often been seen to be controversial, largely because of a failure to understand how it should be used. Initially treatment was targeted on immediate and relatively rapid weight loss based around centrally acting amphetamine derived compounds. In 1997, concerns were raised about the safety of two of these widely used weight management drugs; namely dexfenfluramine and fenfluramine because of their association with pathological changes to heart valves when used alone or in combination with phentermine (F.D.A., 1997). As a result of these concerns, the manufacturer agreed to withdraw both treatments from the market.

More recent developments by the pharmaceutical industry have resulted from the recognition of the need for long term drug treatment for weight loss and weight loss maintenance. This has resulted in the development and subsequent availability of only three major compounds: orlistat, sibutramine and rimonabant (Fig. 1, 2).

Orlistat is a peripherally acting gastric-lipase inhibitor,
Sibutramine

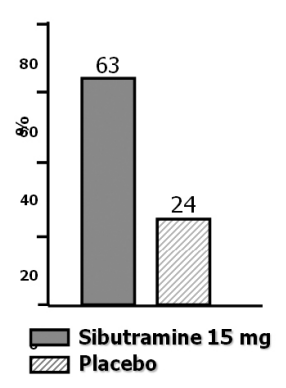

Astrup A. et al. 2001
Orlistat

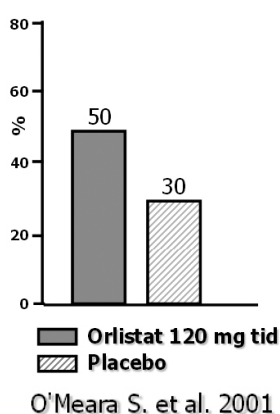

O'Meara S. et al. 2001
Rimonabant

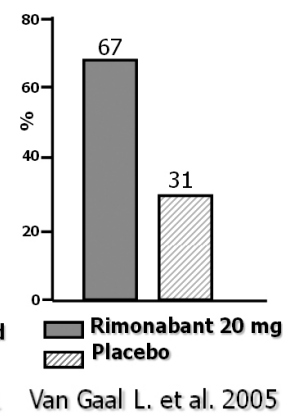

Fig. 1. Percentage of patients achieving $5 \%$ weight loss at 1 year (Completers).

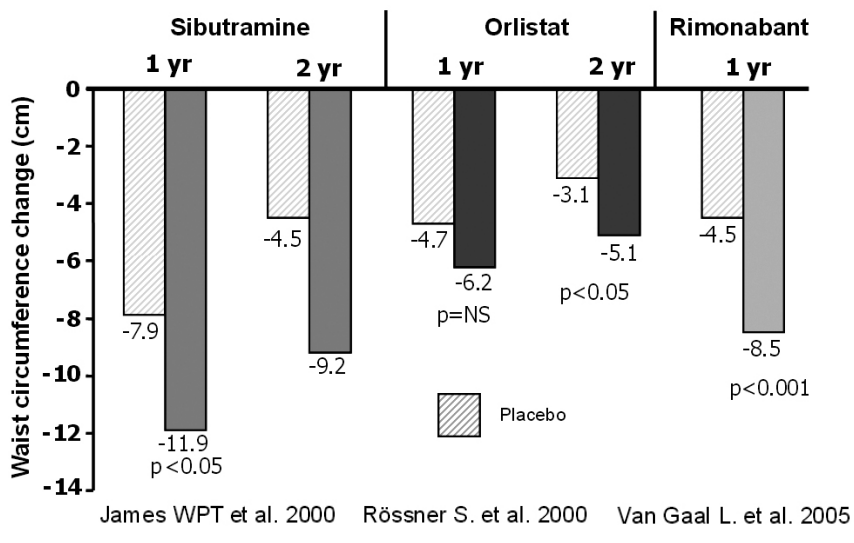

Fig. 2. Effect of weight loss drugs on waist circumference. 
which reduces the up-take of fat within the jejunum and small intestine thereby blocking the hydrolysis of triglycerides, and reducing the absorption of monoacylglycerides and free fatty acids (Guerciolini, 1997). The weightloss efficacy of orlistat has been demonstrated in randomized trials of 1 and 2 years' duration with a second year weight-maintenance phase (Sjöström et al., 1998; Rössner et al., 2000) as well as in a 4-year trial designed to assess both weight loss and the prevention of type 2 diabetes (Torgerson et al., 2004).

The side effects associated with orlistat are principally gastrointestinal in nature, and include malabsorption (urgency of defecation, diarrhea and abdominal discomfort) in patients who exceed 50-60 g dietary fat/day (Padwal and Majumdar, 2007). Due to this local effect, it may be predicted that there could be reduced efficacy in countries where obesity is supported to a lower degree by high-fat diets. A lower-strength preparation with similar short-term efficacy and fewer side effects has been approved for use without a prescription in some countries notably the U.S., Europe and Australia.

Sibutramine is a centrally-acting serotonin and norepinephrine re-uptake inhibitor which acts in the hypothalamus and other CNS areas to increase the activity of neurones which rely on these two neurotransmitters. This reduces energy intake by promoting early termination of eating behavior during a meal and prolonged satiation resulting in significant weight loss (Hansen et al., 1999; Halford et al., 2008). This weight loss would usually be accompanied by a compensatory reduction in energy expenditure, but there is evidence that a secondary effect of sibutramine on metabolic rate (Walsh et al., 1999) attenuates this fall, enhancing weight loss and weight-loss maintenance. Randomised placebo-controlled studies have shown that sibutramine given in conjunction with lifestyle and dietary advice can induce dose-dependent weight loss and maintenance in a wide variety of patient types, including those with comorbidities such as type 2 diabetes (James et al., 2000; McNulty et al., 2003; Hauner et al., 2004).

As a consequence of its peripheral mode of action, treatment with sibutramine in some patients may result in small increases in blood pressure and heart rate and sibutramine is not recommended in patients with uncontrolled hypertension, pre-existing cardiovascular disease, or tachycardia (Padwal and Majumdar, 2007). More recent studies in patients with hypertension, sibutramine was found to initiate a clonidine-like effect leading to an average decrease in blood pressure (Birkenfeld et al., 2002; Heusser et al., 2006).
The third and final drug to be developed for long term weight management was rimonabant, a specific antagonist of the $\mathrm{CB} 1$ receptor of the endocannabinoid system (Cota, 2003). Blocking the CB1 receptor with rimonabant has central nervous system inhibitory effects on food seeking and other "addictive" behaviors, and direct effects through hypothalamic leptin pathways that also reduce food intake and possibly increase energy expenditure. The overall effect was the weight loss demonstrated in the Rimonabant in Obesity trials (RIO programme), which demonstrated similar degrees of weight loss (Despres et al., 2005; Van Gaal et al., 2005; Scheen et al., 2006). However, the drug was linked to an increased risk of psychiatric side effects such as anxiety and depressive disorders probably because it has unwanted effects on 'protective' aspects of an activated brain endocannabinoid system (Christensen et al., 2007) This side-effect profile resulted in an approval rejection by the F.D.A. in the U.S. (F.D.A., 2007) and a voluntary withdrawal by the manufacturer from the market in E.U. countries. As a consequence, other cannabinoid receptor antagonist developments for the treatment of obesity were halted.

These aspects clearly show the difficulties associated with the development of anti-obesity drugs. Although, obesity as a chronic disease requiring long-term therapy has been recognized and proven by all three drugs; sibutramine with STORM (James et al., 2000), orlistat with XENDOS (Torgerson et al., 2004) and with rimonabant in RIO North America (Pi-Sunyer et al., 2006), it is safety over the long term that remains the key issue.

The lack of large-scale outcome studies where pharmacological treatments prove their overall benefit-risk profile seems to be one of the main reasons why such therapies are not widely used, despite the global epidemic of obesity. The ongoing Sibutramine Cardiovascular OUTcomes (SCOUT) trial is the first randomized, prospective study to evaluate the potential benefits of weight management on morbidity and mortality to provide this important information. Over 10,700 overweight or obese patients with cardiovascular risk factors were enrolled in 16 countries world-wide. After a 6-week, single-blind, lead-in period when all patients received $10 \mathrm{mg}$ of sibutramine (James et al, 2005) eligible patients were randomized into a double-blind, placebo-controlled randomization phase. Patients in the lead-in period had significant weight loss $(-2.2 \mathrm{~kg})$, which was associated with reduction in systolic and diastolic blood pressure $(-3 /-1 \mathrm{mmHg}$ ) and a slight, but significant increase in heart rate $(1.5 \mathrm{bpm})$ (Torp-Peterson et al., 2007). The scientific community awaits the overall study data in 2010 . 


\section{FUTURE PERSPECTIVES}

More recent pharmacological targets such as leptin and triple re-uptake inhibitors for serotonin, norepinephrine and dopamine have a difficult path before they can achieve success in the ever-growing market with few pharmaceutical options. It is becoming apparent that the requirement for evidence of a benefit on clinical outcomes seems to be essential for evidence-based medicine which is accepted globally. Furthermore, reassurance of the safety profile of newly-developed compounds appropriate for long-term therapy requires exposure of many patients at great initial cost and high potential failure. This factor alone could be the most important reason why a number of pharmaceutical companies are currently involved in the development of fixed drug combinations of already existing products with known side-effect profiles - hoping to increase the efficacy of products with limited or minimal weight loss properties by combination with other similar low-efficacy drugs. Vivus Inc. (Vivus, 2009) have reported successful phase III data of their amphetamine combination of phentermine with topiramate. In accordance to the Company's press release, this product showed weight loss of over $13 \%$ in study completers. Orexigen Therapeutics (Orexigen, 2009) released somewhat lower efficacy data for their combination of the antidepressant bupropion - an aminoketone selective norepinephrine/dopamine re-uptake inhibitor and the opioid receptor antagonist, naltrexone. Regardless of their promising efficacy data, even with well-established mono-compounds, their medical and commercial success will be dependent on scientific evidence proven through long-term cardiovascular outcome trials in obese patients.

In the presence of a dramatically increasing obesity pandemic, new therapeutic targets are of high interest in order to provide alternatives which can not be satisfied with our current treatment armamentarium. The established medications have limitations in terms of the patients that can benefit; thus there is a continuous and growing unmet need for new efficacious and safe therapies for this disease. Research efforts look toward certain hormones such as ghrelin and leptin which are associated with satiety and energy expenditure. So far, ghrelin blockade is known to reduce hunger, however, since ghrelin has other neurological functions, the therapeutic window of specific inhibitors needs to be carefully assessed, this includes the "vaccine approach" with ghrelin-directed antibodies.

The satiety hormone leptin is another option which is under investigation for the treatment of obesity. However, at this point in time its major limitation is the absence of an approved oral formulation which makes long-term treat- ment cumbersome and unpractical. Future research could target formulation development and the search of a smaller molecule which mimics the structure of leptin but is bioavailable after oral administration. For all these new targets the key questions remains: Will these approaches provide safe and efficacious treatments for our patients?

\section{CONFLICT OF INTEREST}

All authors of this review article are full-time employees of Abbott laboratories. Abbott labs. is the owner of sibutramine, one of the products described in this paper. All author receive their full wages and stocks (some authors) from Abbott labs.

\section{REFERENCES}

Birkenfeld, A. L., Schroeder, C., Boschmann, M., Tank, J., Franke, G., Luft, F. C., Biaggioni, I., Sharma, A. M. and Jordan, J. (2002). Paradoxical effect of sibutramine on autonomic cardiovascular regulation. Circulation 106, 2459-2465.

Christensen, R., Kristensen, P. K., Bartels, E. M., Bliddal, H. and Astrup, A. (2007). Efficacy and safety of the weight-loss drug rimonabant: a meta-analysis of randomised trials. Lancet 370, 1706-1713.

Cota, D., Marsicano, G., Tschöp, M., Grübler, Y., Flachskamm, C., Schubert, M., Auer, D., Yassouridis, A., Thöne-Reineke, C., Ortmann, S., Tomassoni, F., Cervino, C., Nisoli, E., Linthorst, A. C. E., Pasquali, R., Lutz, B., Stalla, G. K. and Pagotto, U. (2003). The endogenous cannabinoid system affects energy balance via central orixegenic drive and peripheral lipogenesis. J. Clin. Invest. 112, 423-431.

Després, J. P., Golay, A. and Sjöström, L. for the Rimonabant in Obesity-Lipids Study Group. (2005). Effects of rimonabant on metabolic risk factors in overweight patients with dyslipidemia. N. Engl. J. Med., 353, 2121-2134.

Eriksson, K. F. and Lindgärde, F. (1998). No excess 12-year mortality in men with impaired glucose tolerance who participated in the Malmö Preventive Trial with diet and exercise. Diabetologia 41, 1010-1016.

F.D.A. U.S. Food and Drug Administration Center for Drug Evaluation and Research. (1997). F.D.A. Analysis of Cardiac Valvular Dysfunction with Use of Appetite Suppressants. Available: http://www.fda.gov/cder/news/slides/index.htm [1997, Sep 17].

Guerciolini, R. (1997). Mode of action of orlistat. Int. J. Obes. Relat. Metab. Disord. 21(Suppl 3), S12-23.

Halford, J. C. G., Boyland, E. J., Cooper, S. J., Dovey, T. M., Huda, M. S. B., Dourish, C. T., Dawson, G. R. and Wilding, J. P. H. (2008). The effects of sibutramine on the microstructure of eating behaviour and energy expenditure in obese women. J. Psychopharmacology 1-11 (e-pub ahead of print).

Hansen, D. L., Toubro, S., Stock, M. J., Macdonald, A. I. and Astrup, A. (1999). The effect of sibutramine on energy expenditure and appetite during chronic treatment without 
dietary restriction. Int. J. Obes. Relat. Metab. Disord., 23, 1016-1024.

Hauner, H., Meier, M., Wendland, G., Kurscheid T., Lauterbach, K. and S.A.T. Study Group. (2004). Weight reduction by sibutramine in obese subjects in primary care medicine: the SAT Study. Exp. Clin. Endocrinol. Diabetes 112, 201-207.

Heusser, K., Tank, J., Diedrich, A., Engeli, S., Klaua, S., Krüger, N., Strauss, A., Stoffels, G., Luft, F. C. and Jordan, J. (2006). Influence of sibutramine treatment on sympathetic vasomotor tone in obese subjects. Clin. Pharmacol. Ther., 79, 500-508.

Huxley, R., James, W. P., Barzi, F., Patel, J.V., Lear, S. A., Suriyawongpaisal, P., Janus E, Caterson, I., Zimmet, P., Prabhakaran, D., Reddy, S., Woodward, M. and The Obesity in Asia Collaboration. (2008). Obes. Reviews 9, S1, 53-61.

James, W. P. T., Astrup, A., Finer, N., Hilsted, J., Kopelman, P., Rössner, S., Saris, W. H. M. and Van Gaal, L. F. for the STORM Study Group. (2000). Effect of sibutramine on weight maintenance after weight loss: a randomised trial. Lancet 356, 2119-2125.

Lopez, A. D., Mathers, C. D., Ezzati, M., Jamison, D. T., Murray, C. L. J., (Eds.). (2006). Global Burden of Disease and Risk Factors. New York. Oxford University Press.

McNulty, S. J., Ur, E. and Williams, G. for The Multicenter Sibutramine Study Group. (2003). A randomized trial of sibutramine in the management of obese type 2 diabetic patients treated with metformin. Diabetes Care 26, 125-131.

Neal, B., Chapman, N. and Patel, A. (2002). Managing the global burden of cardiovascular disease. Eur. Heart J., 4 (Suppl F), F2-F6.

Orexigen Company Press Release. (2009). Available at: http://ir.orexigen.com/phoenix.zhtml?c=207034\&p=irolnews Article\&ID=1308920\&highlight=obesity.

Padwal, R. S. and Majumdar, S. R. (2007). Drug treatments for obesity: orlistat, sibutramine, and rimonabant. Lancet $\mathbf{3 6 9}$, 71-77.

Pi-Sunyer, F. X., Aronne, L. J., Heshmati, H. M., Devin, J. and Rosenstock, J. for the RIO-North America Study Group. (2006). Effect of rimonabant, a cannabinoid-1 receptor blocker, on weight and cardiometabolic risk factors in overweight or obese patients - RIO-North America: a randomized controlled trial. J. Am. Med. Assoc., 295, 761-775.

Prospective Studies Collaboration. (2009). Body-mass index and cause-specific mortality in 900000 adults: collaborative analyses of 57 prospective studies. Lancet 373, 1083-1096.

Scheen, A. J., Finer, N., Hollander, P., Jensen, M. D. and Van Gaal, L. F. for the RIO-Diabetes Study Group. (2006). Efficacy and tolerability of rimonabant in overweight or obese patients with type 2 diabetes: a randomized controlled study. Lancet 368, 1660-1672.

Sjöström, L., Narbro, K., Sjöström, C.D., Karason, K., Larsson, B., Wedel, H., Lystig, T., Sullivan, M., Bouchard, C. Carlsson, B., Bengtsson, C., Dahlgren, S., Gummesson, A., Jacobson, P., Karlsson, J., Lindroos, A. K., Lönroth, H., Näslund, I., Olbers, T., Stenlöf, K., Torgerson, J., Ågren, G. and Carlsson, L. M. S. for the Swedish Obese Subjects Study. (2007). Effects of bariatric surgery on mortality in Swedish obese subjects. N. Engl. J. Med., 357, 741-752.

Sjöström, L., Rissanen, A., Andersen, T., Boldrin, M., Golay, A. Koppeschaar, H. P. and Krempf, M. (1998). Randomised placebo-controlled trial of orlistat for weight loss and prevention of weight regain in obese patients. European Multicentre Orlistat Study Group Lancet 352, 167-172.

Torgerson, J. S., Hauptman, J., Boldrin, M. N. and Sjöström, L. (2004). XENical in the Prevention of Diabetes in Obese Subjects (XENDOS) Study. A randomized study of orlistat as an adjunct to lifestyle changes for the prevention of type 2 diabetes in obese patients. Diabetes Care 27, 155-161.

Walsh, K. M., Leen, E. and Lean, M.E. (1999). The effect of sibutramine on resting energy expenditure and adrenalineinduced thermogenesis in obese females. Int. J. Obes. Relat. Metab. Disord., 23, 1009-1015.

W.H.O. Expert Consultation. (2004). Appropriate body-mass index for Asian populations and its implications for policy and intervention strategies. Lancet 363, 157-163.

Yusuf, S., Hawken, S., Ôunpuu, S., Bautista, L., Franzosi, M. G., Commerford, P., Lang, C. C., Rumboldt, Z., Onen, C. L., Lisheng, L., Tanomsup, S., Wangai P., Razak, F., Sharma, A. M. and Anand, S. S. on behalf of the INTERHEART Study Investigators. (2005). Obesity and the risk of myocardial infarction in 27000 participants from 52 countries: a case-control study. Lancet 366, 1640-1649.

Yusuf, S., Hawken, S., Ôunpuu, S., Dans, T., Avezum, A., Lanas, F., McQueen, M., Budaj, A., Pais, P., Varigos, J. and Lisheng, L. on behalf of the INTERHEART Study Investigators. (2004). Effect of potentially modifiable risk factors associated with myocardial infarction in 52 countries (the INTERHEART study): case-control study. Lancet 364 (9438), 937-952. 